\title{
Clostridium difficile exposure as an insidious source of infection in healthcare settings: an epidemiological model
}

\author{
Laith Yakob ${ }^{1 *}$, Thomas V Riley ${ }^{2}$, David L Paterson ${ }^{3}$ and Archie CA Clements ${ }^{1}$
}

\begin{abstract}
Background: Clostridium difficile is the leading cause of infectious diarrhea in hospitalized patients. Its epidemiology has shifted in recent years from almost exclusively infecting elderly patients in whom the gut microbiota has been disturbed by antimicrobials, to now also infecting individuals of all age groups with no recent antimicrobial use.

Methods: A stochastic mathematical model was constructed to simulate the modern epidemiology of $C$. difficile in a healthcare setting, and, to compare the efficacies of interventions.

Results: Both the rate of colonization and the incidence of symptomatic disease in hospital inpatients were insensitive to antimicrobial stewardship and to the prescription of probiotics to expedite healthy gut microbiota recovery, suggesting these to be ineffective interventions to limit transmission. Comparatively, improving hygiene and sanitation and reducing average length of stay more effectively reduced infection rates. Although the majority of new colonization events are a result of within-hospital ward exposure, simulations demonstrate the importance of imported cases with new admissions.

Conclusions: By analyzing a wide range of screening sensitivities, we identify a previously ignored source of pathogen importation: although capturing all asymptomatic as well as symptomatic introductions, individuals who are exposed but not yet colonized will be missed by even a perfectly sensitive screen on admission. Empirical studies to measure the duration of this latent period of infection will be critical to assessing $C$. difficile control strategies. Moreover, identifying the extent to which the exposed category of individual contributes to pathogen importation should be explicitly considered for all infections relevant to healthcare settings.
\end{abstract}

\section{Background}

Clostridium difficile is a Gram-positive, toxin-producing anaerobic bacterium. Worldwide, it is the leading cause of infectious diarrhea in hospitalized patients. The incidence and severity of $C$. difficile infection (CDI) varies considerably among studied populations but the general trend shows an increase in recent decades [1-3], with a higher proportion of CDI patients undergoing colectomy and dying $[4,5]$. The disease is currently estimated to cost $\$ 800$ million per year in US acute care facilities [6]. Previously, persistently disturbed intestinal microbiota, usually as a result of antimicrobials, was considered a prerequisite of the disease. However, recent studies have

\footnotetext{
*Correspondence: laith.yakob@uq.edu.au

'School of Population Health, The University of Queensland, Brisbane, Australia

Full list of author information is available at the end of the article
}

demonstrated severe cases occurring in groups that were previously assumed to be low-risk, including pregnant women, children and people with no recent exposure to antimicrobials $[7,8]$, indicating either a changing epidemiology or more testing in these groups [9].

There is increasing evidence for a potentially important role of asymptomatic carriage in the epidemiology of CDI [10], with increasing rates recorded within healthcare settings [11] and for the wider community $[12,13]$. Hospital rooms occupied by asymptomatic patients can have very high rates of contamination (29\%) [14]. The dissociation between symptoms and infectivity was recently corroborated by a prospective clinical study in which $60 \%$ of patients still had skin contamination following resolution of diarrhea in CDI patients, and $37 \%$ continued to shed spores in their stool [15]. Carriers have been implicated in the global spread of hyper- 
virulent strains such as ribotype 027 which is believed to have caused over 2000 fatalities during the 2003-4 outbreak in Quebec, Canada [16]. Increased incidence, severity of disease associated with endemic strains and frequency of outbreaks emphasize the urgency for improved epidemiological understanding. To this end, we construct the most comprehensive epidemiological model of CDI transmission reported to date and use it to compare the efficacies of key interventions.

Surprisingly, there are only three modeling studies describing the mechanism of CDI transmission, each providing insight but with important limitations. The first mathematical model of CDI by Starr and colleagues [17] ignored asymptomatic carriage, a major potential source of infection for this disease $[11,18]$. While this omission was rectified by the authors in a subsequent study [19], differential rates of progression to symptomatic disease between patients who were and who were not taking antimicrobials [20] were not accounted for. The third modeling study [21], developed by Lanzas and colleagues, did not allow for symptomatic disease in patients who were not on antimicrobials thereby overlooking a growing body of research showing high incidence rates in previously healthy individuals to be a key feature of $C$. difficile epidemiology [22,23]. Although parsimony should always be a goal of epidemiological models, the inclusion of greater biological realism in our simulations highlights a hitherto unreported and potentially significant source of infection. We use this stochastic model to assess and compare the efficacies of several interventions to reduce infection transmission. We discuss the significance of our findings to infectious disease transmission within healthcare settings in general as well as specifically to the epidemiology of CDI.

\section{Methods}

\section{The $C$. difficile pathogen}

C. difficile is transmitted via the fecal-oral route. The infectious dose is small and the bacterium is capable of producing spores which can remain viable for years in the environment [24]. There has been a recent suggestion of inhalation of spores potentially providing a secondary mode of transmission $[25,26]$, but this is unlikely to contribute significantly to the disease's epidemiology. On ingestion, the pathogen colonizes the gut and the host typically sheds bacteria in their stool within two weeks.

A significant proportion of infections is asymptomatic, with a spectrum of symptoms of varying severity experienced by the remainder [14,27]. These symptoms include diarrhea, fever and abdominal pain and can result in toxic megacolon and death. Reasons for the development of symptomatic infection are incompletely understood but the risk factor most commonly associated with this progression is the disruption of normal gut microbiota by antimicrobials [28]. As a consequence of disrupted gut microbiota and lack of local immunity, the treatment of symptomatic infection with antimicrobials is met with high relapse rates in patients who do not successfully clear infection, as well as high reinfection rates [29]. Our model is the first that allows for treated individuals to return back to asymptomatically infected, exposed or uncolonized states to reflect the fact that treatment success is so variable. Following recent evidence of an increasing trend in colonization and disease in individuals who have not recently received antimicrobials [8], our model allows for the development of CDI without antibiotic involvement.

\section{Epidemiological model parameterization}

Patients in a hospital with 1000 beds were simulated for 1 year. Individuals were stratified according to infection status (Unexposed, Exposed, Colonized or Diseased) and whether or not they were currently taking antimicrobials (or had taken antimicrobials within the last 3 months). Exposed, colonized and diseased patients all harbor the pathogen; colonized and diseased patients contribute to transmission, but only diseased patients exhibit symptoms. The overall structure of the model is described in Figure 1. One novel component of our study is the incorporation of an 'Exposed' class of individuals which explicitly allows for the fact that individuals who are not colonized on admission may subsequently become colonized regardless of within-hospital exposure. The epidemiological consequences of this addition are discussed fully after the analysis.

Average length of stay was assumed to be 6 days, reflecting rates that are typical of the US, Europe and Australia [30]. Patients could be admitted in any of the seven possible states but only discharged if they were not suffering from symptomatic disease. The proportion of new admissions that was taking (or had recently taken) antimicrobials was assumed to be $25 \%$ and the rates of antimicrobial prescription assumed that $50 \%$ of the hospital inpatients were currently on antimicrobials (or had taken them in the previous 3 months) [31,32]. Recovery of gut microbiota following cessation of antimicrobial treatment was assumed to take 3 months [33]. New admissions were assumed to perfectly balance discharges, resulting in a constant population size that experienced frequency-dependent transmission. This is typical for the epidemiological modeling of human infectious diseases [34].

After a period of 5 days, exposed individuals became asymptomatically colonized [35]. For patients on antimicrobials, progression to symptomatic disease took a further 5 days [20]. Patients not on antimicrobials were assumed to be five-times less likely to progress to 


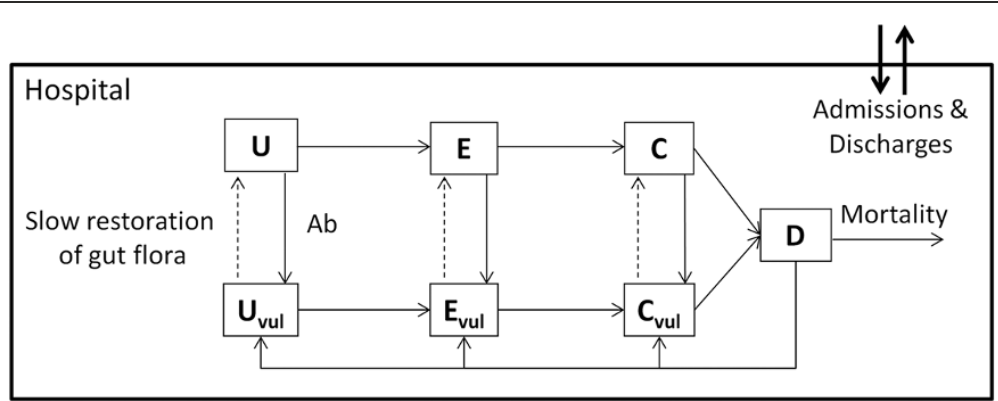

Figure 1 Compartmental design of epidemiological model for Clostridium difficile. Individuals are either 'U'nexposed, 'E'xposed, 'C'olonized or 'D'iseased and are increasingly 'vul'nerable when they have taken antimicrobials ('Ab'). Patients of all epidemiological states can be admitted but only discharged if not symptomatic.

symptomatic disease [20]. Cure rate following treatment, which took 10 days [36], was assumed to be $80 \%$ [37], with the remaining treated patients returning to the exposed category. The symptoms of $33 \%$ of patients with CDI self-resolved [38] and $2 \%$ of symptomatic CDI patients died [20]. Table 1 summarizes the model parameters and definitions with associated cited studies.

\section{Mathematical model construction}

Ordinary differential equations were constructed to reflect the biology of infection as parsimoniously as possible (Additional file 1). Traditionally, the basic reproduction number, R0, is used to estimate transmission potential of an infectious disease. R0 is a useful metric for estimating outbreak thresholds and is therefore of relevance in estimating risk of epidemic strains introduced into fully susceptible (disease-free) populations. The stable endemicity of $C$. difficile within healthcare settings represents a significant departure from a disease-free population. Moreover, R0 no longer quantifies risk nor discriminates between high levels and low levels of transmission when constant imports of pathogen are accounted for in healthcare settings [39].
Therefore, we present our results of control simulations in terms of the incidence of symptomatic disease and the ratio of colonized patients discharged from hospital relative to patients colonized on admission. An advantage of these measures of intervention efficacy is that they can be directly measured.

Because the simulated population is small, infection dynamics are more likely to be governed by stochastic processes. Therefore, the ordinary differential equations were converted into a stochastic simulation system based on Gillespie's direct method [40]. This method of simulation accounts for continuous time but discrete state space whereby the probability of conversion from one state (e.g., Exposed) to another (e.g., Colonized) is determined by the associate rate of the ordinary differential equation system. There are 15 possible epidemiological state transitions in this system and they are summarized in Table 2. The table shows the transfer of individuals from one epidemiological compartment (“-1") to another ("+1").

This stochastic model was used to compare the efficacy of four different control measures in reducing the rate of colonization within the hospital as well as the

Table 1 Epidemiological model symbology and parameterization

\begin{tabular}{|c|c|c|c|}
\hline Parameter & Definition & Value (,Vul) & Reference \\
\hline$\lambda$ & Recovery of gut microbiota $\left(\right.$ day $\left.^{-1}\right)$ & 0.011 & 33 \\
\hline$a$ & Antibiotic treatment $\left(\right.$ day $\left.^{-1}\right)$ & 0.11 & 31,32 \\
\hline$\beta$ & Exposure $\left(\right.$ day $\left.^{-1}\right)$ & Full range SIM & \\
\hline$\eta$ & Dev into asympt infectious (day ${ }^{-1}$ ) & $0.2,0.2$ & 35 \\
\hline$\theta$ & Dev symptomatic CDI $\left(\right.$ day $\left.^{-1}\right)$ & $0.04,0.2$ & 20 \\
\hline$\rho$ & $\mathrm{CDI}$ treatment $\left(\right.$ day $\left.^{-1}\right)$ & 0.1 & 36 \\
\hline$\sigma$ & Treatment failure (prop.) & 0.2 & 37 \\
\hline$\zeta$ & Self-resolving symptoms (prop.) & 0.33 & 38 \\
\hline$\mu$ & CDI case fatality rate (prop.) & 0.02 & 20 \\
\hline$\kappa$ & Hospital discharge $\left(\right.$ day $\left.^{-1}\right)$ & 0.17 & 30 \\
\hline$\varepsilon$ & Hospital admission (proportion) & $0.75,0.25$ & 31,32 \\
\hline$Q$ & Quarantined CDI ' 0 ' yes, ' 1 ' no & $\mathrm{n} / \mathrm{a}$ & \\
\hline
\end{tabular}


Table 2 Epidemiological state transitions of the event-driven, stochastic model

\begin{tabular}{|c|c|c|}
\hline Event & Transition probability & State change \\
\hline Antibiotic treatment of uncolonized individual & $a \cup \delta t$ & $U-1, U_{v}+1$ \\
\hline exposed individual & $a E \delta t$ & $E-1, E_{v}+1$ \\
\hline colonized individual & $a c \delta t$ & $C-1, C_{v}+1$ \\
\hline Gut microbiota recovery of uncolonized individual & $\lambda U_{v} \delta t$ & $U_{v}-1, U+1$ \\
\hline exposed individual & $\lambda E_{v} \delta t$ & $E_{v}-1, E+1$ \\
\hline colonized individual & $\lambda C_{\vee} \delta t$ & $C_{v}-1, C+1$ \\
\hline Exposure of individual without recent $A b$ use & $\beta\left[\left(C+C_{V}+D Q\right) \cup / N\right] \delta t$ & $U-1, E+1$ \\
\hline individual with recent $\mathrm{Ab}$ use & $\beta\left[\left(C+C_{v}+D Q\right) U_{v} / N\right] \delta t$ & $U_{v}-1, E_{v}+1$ \\
\hline Colonization of individual without recent Ab use & $\eta E \delta t$ & $E-1, C+1$ \\
\hline individual with recent $A b$ use & $\eta E_{v} \delta t$ & $E_{v}-1, C_{v}+1$ \\
\hline Symptoms develop in indiv. without recent $A b$ use & $\theta C \delta t$ & $C-1, D+1$ \\
\hline individual with recent $\mathrm{Ab}$ use & $\theta_{v} C v \delta t$ & $C_{v}-1, D+1$ \\
\hline Symptoms resolve & $\zeta D \delta t$ & $D-1, C_{v}+1$ \\
\hline Full clearance following treatment & $(1-\sigma) \rho D \delta t$ & $D-1, U_{v}+1$ \\
\hline Treatment does not result in full clearance & $\sigma \rho D \delta t$ & $D-1, E_{v}+1$ \\
\hline
\end{tabular}

incidence of symptomatic CDI. These controls were 1) reducing the rate of antimicrobial prescription in order to minimize the proportion of patients with heightened vulnerability to symptomatic disease, 2) reducing the level of environmental contamination and improving hand hygiene, 3) administering probiotics to expedite the restoration of healthy gut microbiota, and, 4) the reduction of average length of stay of inpatients.

The importance of asymptomatic patients in infection transmission is a topic that has received a lot of recent interest $[10,11,41,42]$. Despite this, the incubation periods for $C$. difficile are less well defined than for other pathogens [9]. Simulating infection dynamics across a wide range of incubation periods, we assessed the applicability of screening for asymptomatic, as well as symptomatic, admissions. Recent developments in commerciallyavailable PCR screening technology have provided a sensitive $(\sim 90 \%)$ tool for rapidly detecting $(\sim 2 \mathrm{~h})$ colonization with $C$. difficile [43]. Therefore, we gauged the utility of this screen as a further method of intervention under the assumption that hospitals have the facilities to segregate colonized (both asymptomatic and symptomatic) and non-colonized patients.

\section{Results and discussion}

The temporal output from a typical stochastic simulation run, using baseline parameterization and in the absence of intervention is shown in Figure 2. The top panel shows the percentage of colonized individuals discharged compared with the percentage of colonized admissions. Average colonization prevalence on admission was $4.0 \%$ (st. dev. 2.0) which closely matches a recent Canadian study that measured asymptomatic admission prevalence of $4.4 \%$ in 6 hospitals in Quebec 2006-2007 [20]. We could not find clinical studies measuring the prevalence of colonization on discharge to directly corroborate our simulated values. However, in our study, colonization and length of stay are independent variables and so prevalence in discharged patients is representative of inpatient prevalence. Hospital inpatient prevalence of endemic $C$. difficile varies a

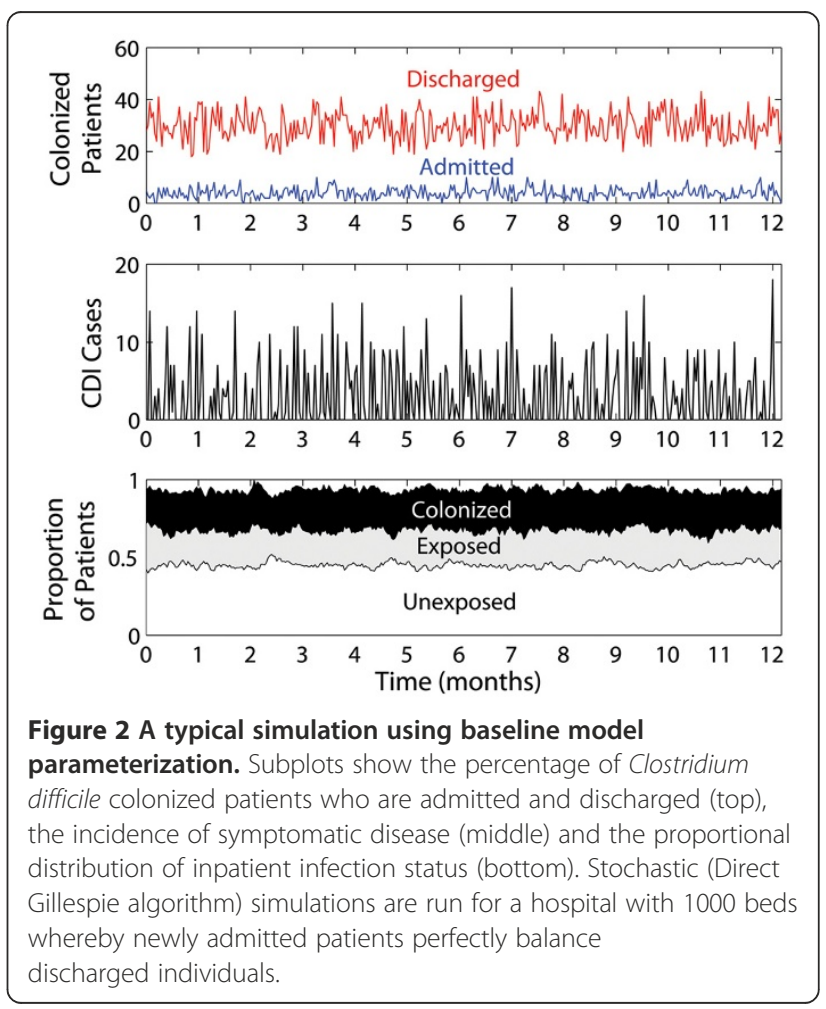


great deal over time and between different locations, but our average colonization prevalence of $30 \%$ (st. dev. $5.6 \%)$ falls within the range described in the clinical literature [44].

The middle panel of Figure 2 shows the incidence of symptomatic $C$. difficile infection which averages 2.8 cases per 1000 hospital bed days (st. dev. 4.2), also within the range described in the most comprehensive pan-European survey [45]. The very high rates of underreporting that are known to occur for this pathogen, especially in younger patients who have less severe symptoms, suggest that the true prevalence of infection lies towards the top-end of estimates [46]. The bottom panel shows the proportional distribution of the epidemiological states of hospital inpatients in which the ratio of total (vulnerable or otherwise) Unexposed: Exposed: Colonized: Diseased patients is 0.45: 0.26: 0.24: 0.05 . Importantly, our baseline parameterization using the most up-to-date data available for this pathogen suggests that there are as many individuals in the 'Exposed' category as in the 'Colonized' category.

Figure 3 shows the sensitivity of two different outputs (ratio of colonized patients discharged compared with on admission, and, the incidence of symptomatic CDI), to the four model parameters pertaining to control namely, the rate of antimicrobial prescription, the transmission coefficient (reduced by improved hygiene and

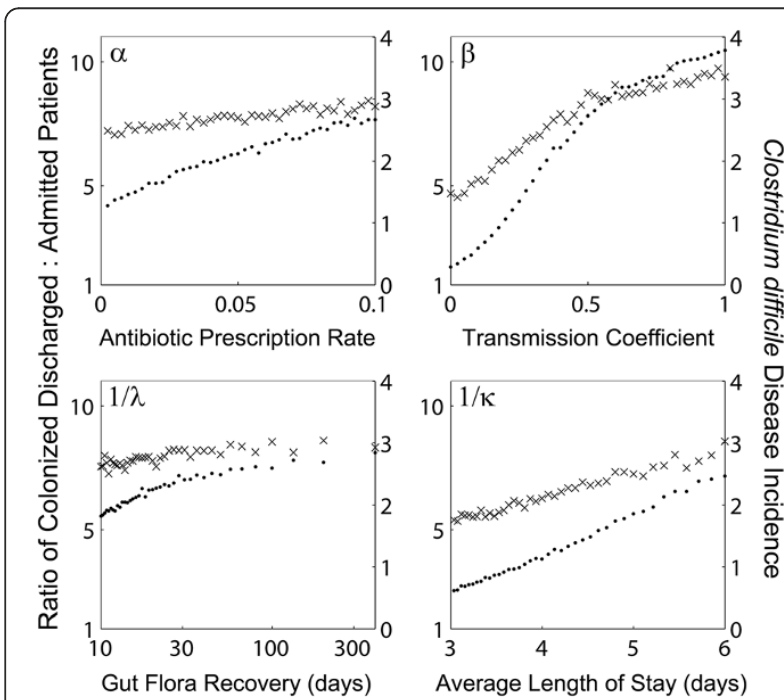

Figure 3 The effects of different control measures on Clostridium difficile in the simulated hospital. The ratio of patients colonized with $C$. difficile when discharged compared to new admissions (left $Y$ axis, points) are shown along with associated incidence of symptomatic disease per 1000 hospital bed days (right $Y$ axis, crosses) across a wide range of the four tested control measures: reducing antimicrobial prescription (top-left), improved sanitation and hygiene (top-right), administering pro-biotics (bottom-left) and reducing the average length of stay (bottomright). Each point is the average value of a 1-year simulation. sanitation), gut microbiota recovery rate (expedited with probiotics) and average length of stay. Projections from the model reinforce the clinical evidence supporting a reduced length of stay $[47,48]$ and infection control [49-51] as effective methods for attenuating the spread of $C$. difficile. While there is reassuring agreement between our model projections and clinical records of intervention efficacy, there is also an important disparity worth noting. Several recent studies have suggested antimicrobial stewardship to be an effective method of reducing the rate of CDI in hospitals [52-55]. However, these include studies that examined stewardship in conjunction with infection control procedures $[54,55]$, thereby obscuring the efficacy of reduced prescription rates alone. They also include studies that found either borderline significant reduction in $\mathrm{CDI}(\mathrm{P}=0.04$, [53]) or no statistical significance through a reduction in either high-risk drugs or total antimicrobial usage in healthcare settings (respectively, $\mathrm{P}=0.0597$ and $\mathrm{P}=0.0823$, [52]). Therefore, the conflicting evidence for CDI reduction through antimicrobial stewardship is in keeping with a small effect size, as demonstrated by our simulations.

Infection rates were also insensitive to increased gut microbiota recovery promoted by probiotics. Cautious interpretation of this result is urged because while we found the overall influence that this treatment has on population-level transmission dynamics to be minimal, it does not necessarily negate the individual-level health benefits of probiotics.

Comparatively much greater returns were achieved by reducing the length of stay and through improved hygiene (respectively, bottom-right and top-right panel Figure 3). Halving the average inpatient length of stay yielded almost a 3 -fold reduction in the colonized ratio of discharged compared with admitted patients. Additionally, a 10-fold decrease in CDI incidence was theoretically possible through improved hygiene and sanitation practices. However, even in this scenario whereby complete elimination of within-ward exposure was achieved $(\beta=0)$, more patients left the hospital colonized than when they arrived. This is due to the expedited progression of disease resulting from antimicrobials, suggesting that stewardship might come into play as a more influential control tool once initial efforts have already eliminated ward-based transmission.

A thorough sensitivity analysis of model input parameters (see Additional file 2) demonstrates the robustness of our results pertaining to infection control. However, there are several limitations of this study that will require additional development and refinement. The lifecourse of the pathogen is incompletely understood. Our model structure assumes that all individuals who become symptomatic must first pass through a phase of shedding the pathogen asymptomatically. This follows 
on from the very comprehensive epidemiological study carried out by Loo and coauthors in which the time to developing symptomatic disease was measured to be twice that for developing asymptomatic colonization [20]. An alternative interpretation of this finding would be that the individuals who develop symptomatic infection never pass through a phase of asymptomatic shedding, but, instead, have a delayed progression of colonization. However, this would imply that successful colonization within patients that develop symptomatic disease is somehow delayed. In the absence of definitive evidence, therefore, our assumption seems more likely. Another limitation of the study is the assumption that asymptomatic shedders contribute equivalently to transmission as symptomatically infected individuals. While symptomatic disease involves a greater bacterial load, asymptomatic shedding would not prompt the same level of cautiousness in hygiene practices. Ascertaining the relative contributions of both category of individual will be a difficult, but important, issue to reconcile. Once good, reproducible data become available on this difference, the model can easily be adjusted to incorporate the additional information. A further limitation is the lack of consideration for healthcare professionals (and, also, hospital visitors) as vectors of infection - again, something that will require further development when the epidemiological data become available. Greater complexity can be iteratively incorporated into the framework presented here to explore additional risk factors including patient age as well as underlying co-morbidities and patient immune status. Future directions for this work also include assessing the integration of control tools. Integrated control has been strategized with mathematical models for a number of infectious diseases including sexually transmitted infections [56,57], vector-borne diseases [58-60], newly emerging infections and pathogenic bioterrorism attacks $[61,62]$. However, research into strategic combinations of healthcare-acquired infection control methods is underdeveloped.

Finally, we measured the sensitivity of the colonization ratio and the incidence of CDI on the pathogen's incubation period - the $C$. difficile life history parameter of greatest uncertainty [9]. Intuitively, for shorter incubation periods, the colonization ratio increased along with CDI incidence (Figure 4). This is because longer incubation periods delay the rate at which a pathogen can spread between individuals. Remarkably, however, infection rates were extremely insensitive to screening sensitivity. Even where screening was 100\% sensitive (current leading rapid screen sensitivity is $~ 90 \%$ ) [43], little impact on infection rates was achieved by the segregation of all colonized admissions from non-colonized inpatients. Recent studies have suggested that a large proportion of patients colonized with $C$. difficile in healthcare

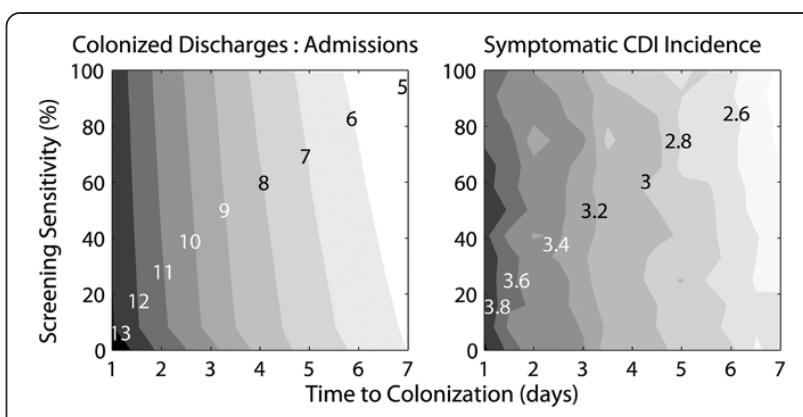

Figure 4 The effects of screening on Clostridium difficile in the simulated hospital. The ratio of patients that are colonized with $C$. difficile when discharged relative to on admission (left) are shown along with the associated incidence in symptomatic CDI per 1000 hospital bed days (right). Even highly sensitive screening ( $Y$ axis) can do little to impact either of these epidemiological outcomes.

However, time to colonization ( $X$ axis), a component of the pathogen's life course for which data is absent, is highly influential in its epidemiology.

settings was likely exposed to the pathogen before they were admitted $[11,21,41,42]$. These authors thereby attribute a substantial role of asymptomatic individuals on the importation of infection. In this analysis, by screening and subsequently isolating both asymptomatic and symptomatic patients from the non-colonized inpatients, we have eliminated these sources of infection and uncovered a previously ignored and potentially important source of $C$. difficile in healthcare settings: new admissions who have been exposed to the pathogen but not yet colonized.

\section{Conclusions}

Even a perfect screening test giving immediate results for all new admissions will fail to detect the carriage of $C$. difficile into the hospital by patients. Although obtaining good estimates of the incubation period has proven particularly difficult [9], it will be critical to uncovering the extent to which the exposed category of individuals influences the epidemiology of CDI. This finding is not only relevant to C. difficile epidemiology, but to any pathogen that can be undetectably transported by exposed individuals.

\section{Additional files}

Additional file 1: Ordinary differential equations describing the framework of Clostridium difficile infection transmission.

Additional file 2: Sensitivity analysis of the stochastic Clostridium difficile mathematical model.

\section{Competing interests}

The authors declare that they have no competing interests. 


\section{Authors' contributions}

LY, TVR, DLP and ACAC contributed towards the design of the model. LY constructed and analyzed the model. LY, TVR, DLP and ACAC wrote initial drafts of the manuscript. LY, TVR, DLP and ACAC read and approved the final manuscript.

\section{Acknowledgements}

The authors thank Camilla Wiuff and Jan Lindstrom for their useful comments. The study was supported by funding from the National Health and Medical Research Council of Australia, grant number APP1006243.

\section{Author details}

'School of Population Health, The University of Queensland, Brisbane, Australia. ${ }^{2}$ School of Pathology and Laboratory Medicine, University of Western Australia, Crawley, Australia. ${ }^{3}$ Centre for Clinical Research, The University of Queensland, Brisbane, Australia.

\section{Received: 18 March 2013 Accepted: 13 August 2013}

Published: 16 August 2013

\section{References}

1. McDonald $L C$, Owings $M$, Jernigan DB: Clostridium difficile infection in patients discharged from US short-stay hospitals, 1996-2003. Emerg Infect Dis 2006, 12(3):409-415.

2. Wilcox MH, Smyth ET: Incidence and impact of clostridium difficile infection in the UK, 1993-1996. J Hosp Infect 1998, 39(3):181-187.

3. Lo Vecchio A, Zacur G: Clostridium difficile infection: an update on epidemiology, risk factors, and therapeutic options. Curr Opin Gastroenterol 2012, 28:1-9.

4. Muto CA, Pokrywka M, Shutt K, Mendelsohn AB, Nouri K, Posey K, Roberts T, Croyle K, Krystofiak S, Patel-Brown S, et al: A large outbreak of clostridium difficile-associated disease with an unexpected proportion of deaths and colectomies at a teaching hospital following increased fluoroquinolone use. Infect Control Hosp Epidemiol 2005, 26(3):273-280.

5. Ricciardi R, Rothenberger DA, Madoff RD, Baxter NN: Increasing prevalence and severity of clostridium difficile colitis in hospitalized patients in the united states. Arch Surg 2007, 142(7):624-631.

6. McGlone SM, Bailey RR, Zimmer SM, Popovich MJ, Tian Y, Ufberg P, Muder RR, Lee BY: The economic burden of clostridium difficile. Clin Microbiol Infect 2012, 18(3):282-289.

7. Benson L, Song X, Campos J, Singh N: Changing epidemiology of clostridium difficile-associated disease in children. Infect Control Hosp Epidemiol 2007, 28(11):1233-1235.

8. Clements ACA, Magalhaes RJS, Tatem AJ, Paterson DL, Riley TV: Clostridium difficile PCR ribotype 027: assessing the risks of further worldwide spread. Lancet Infect Dis 2010, 10(6):395-404.

9. Cohen SH, Gerding DN, Johnson S, Kelly CP, Loo VG, McDonald LC, Pepin J, Wilcox MH: Clinical practice guidelines for clostridium difficile infection in adults: 2010 update by the society for healthcare epidemiology of America (SHEA) and the infectious diseases society of america (IDSA). Infect Control Hosp Epidemiol 2010, 31(5):431-455.

10. Curry SR, Muto CA, Schlackman JL, Pasculle AW, Shutt KA, Marsh JW, Harrison LH: Use of MLVA genotyping to determine the role of asymptomatic carriers in C. Difficile transmission. Clin Infect Dis 2013 doi:10.1093/cid/cit475. in press.

11. Riggs MM, Sethi AK, Zabarsky TF, Eckstein EC, Jump RLP, Donskey CJ: Asymptomatic carriers are a potential source for transmission of epidemic and nonepidemic clostridium difficile strains among long-term care facility residents. Clin Infect Dis 2007, 45(8):992-998.

12. Dial S, Delaney JAC, Barkun AN, Suissa S: Use of gastric acid-suppressive agents and the risk of community-acquired clostridium difficileassociated disease. JAMA 2005, 294(23):2989-2995.

13. McFarland LV, Beneda HW, Clarridge JE, Raugi GJ: Implications of the changing face of clostridium difficile disease for health care practitioners. Am J Infect Control 2007, 35(4):237-253.

14. McFarland LV, Mulligan ME, Kwok RY, Stamm WE: Nosocomial acquisition of clostridium difficile infection. N Engl J Med 1989, 320(4):204-210.

15. Sethi A, Al-Nassir W, Nerandzic M, Bobulsky G, Donskey C: Persistence of skin contamination and environmental shedding of clostridium difficile during and after treatment of C. Difficile infection. Infect Control Hosp Epidemiol 2010, 31(1):21-27.
16. Eggertson L: C. Difficile may have killed 2000 in quebec: study. Can Med Assoc J 2005, 173(9):1020-1021.

17. Starr JM, Campbell A: Mathematical modeling of clostridium difficile infection. Clin Microbiol Infect 2001, 7(8):432-437.

18. Clabots CR, Johnson S, Olson MM, Peterson LR, Gerding DN: Acquisition of clostridium difficile by hospitalized patients: evidence for colonized new admissions as a source of infection. J Infect Dis 1992, 166(3):561-567.

19. Starr JM, Campbell A, Renshaw E, Poxton IR, Gibson GJ: Spatio-temporal stochastic modelling of clostridium difficile. J Hosp Infect 2009, 71(1):49-56

20. Loo VG, Bourgault A-M, Poirier L, Lamothe F, Michaud S, Turgeon N, Toye B, Beaudoin A, Frost EH, Gilca R, et al: Host and pathogen factors for clostridium difficile infection and colonization. N Engl J Med 2011, 365(18):1693-1703.

21. Lanzas C, Dubberke ER, Lu Z, Reske KA, Grohn YT: Epidemiological model for clostridium difficile transmission in healthcare settings. Infect Control Hosp Epidemiol 2011, 32(6):553-561

22. Freeman J, Bauer MP, Baines SD, Corver J, Fawley WN, Goorhuis B, Kuijper EJ, Wilcox MH: The changing epidemiology of clostridium difficile infections. Clin Microbiol Rev 2010, 23(3):529-549.

23. Kelly CP, LaMont JT: Clostridium difficile-more difficult than ever. $N$ Engl J Med 2008, 359(18):1932-1940.

24. Rupnik M, Wilcox MH, Gerding DN: Clostridium difficile infection: new developments in epidemiology and pathogenesis. Nat Rev Microbio/ 2009, 7(7):526-536.

25. Best EL, Fawley WN, Parnell P, Wilcox MH: The potential for airborne dispersal of clostridium difficile from symptomatic patients. Clin Infect Dis 2010, 50(11):1450-1457.

26. Roberts K, Smith CF, Snelling AM, Kerr KG, Banfield KR, Sleigh PA, Beggs CB: Aerial dissemination of clostridium difficile spores. BMC Infect Dis 2008, 8:7-7.

27. Kyne L, Merry C, O'Connell B, Kelly A, Keane C, O'Neill D: Factors associated with prolonged symptoms and severe disease due to clostridium difficile. Age Ageing 1999, 28(2):107-113.

28. Bignardi GE: Risk factors for clostridium difficile infection. J Hosp Infect 1998, 40(1):1-15.

29. Johnson S: Recurrent clostridium difficile infection: a review of risk factors, treatments, and outcomes. J Infect 2009, 58(6):403-410.

30. OECD: Health at a Glance 2011: OECD Indicators. OECD Publishing; 2011. doi:10.1787/health_glance-2011-en.

31. MacDougall C, Polk R: Variability in rates of Use of antibacterials among 130 US hospitals and risk-adjustment models for interhospital comparison. Infect Control Hosp Epidemiol 2008, 29:203-211.

32. Polk R, Fox C, Mahoney A, Letcavage JCM: Measurement of adult antibacterial drug Use in 130 US hospitals: comparison of defined daily dose and days of therapy. Clin Infect Dis 2007, 44:664-670.

33. Rafii F, Sutherland J, Cerniglia C: Effects of treatment with antimicrobia agents on the human colonic microflora. Ther Clin Risk Manag 2008, 4:1343-1358.

34. Keeling M, Rohani P: Modeling infectious diseases in humans and animals. Princeton, NJ: Princeton University Press; 2007.

35. Johnson S, Clabots CR, Linn FV, Olson MM, Peterson LR, Gerding DN Nosocomial clostridium difficile colonisation and disease. Lancet 1990 336(8707):97-9100.

36. MCFarland LV: Update on the changing epidemiology of clostridium difficile-associated disease. Nat Clin Pract Gastroenterol Hepatol 2008, 5 (1):40-48.

37. Leffler DA, Lamont JT: Treatment of clostridium difficile-associated disease. Gastroenterology 2009, 136(6):1899-1912.

38. Bartlett JG: Treatment of antibiotic-associated pseudomembranous colitis. Rev Infect Dis 1984, 6(suppl 1):S235-S241.

39. McBryde ES, Pettitt AN, MCElwain DLS: A stochastic mathematical model of methicillin resistant staphylococcus aureus transmission in an intensive care unit: predicting the impact of interventions. J Theor Biol 2007, 245(3):470-481.

40. Gillespie DT: Exact stochastic simulation of coupled chemical reactions. J Phys Chem 1977, 81(25):2340-2361.

41. Muto CA, Blank MK, Marsh JW, Vergis EN, O'Leary MM, Shutt KA, Pasculle AW, Pokrywka M, Garcia JG, Posey K, et al: Control of an outbreak of infection with the hypervirulent clostridium difficile $\mathrm{BI}$ strain in a 
university hospital using a comprehensive "bundle" approach. Clin Infect Dis 2007, 45(10):1266-1273.

42. Walker AS, Eyre DW, Wyllie DH, Dingle KE, Harding RM, O'Connor L, Griffiths D, Vaughan A, Finney J, Wilcox MH, et al: Characterisation of clostridium difficile hospital ward-based transmission using extensive epidemiological data and molecular typing. PLoS Med 2012, 9(2):e1001172

43. Eastwood K, Else P, Charlett A, Wilcox M: Comparison of nine commercially available clostridium difficile toxin detection assays, a real-time PCR assay for $\mathrm{C}$. Difficile $\mathrm{tcdB}$, and a glutamate dehydrogenase detection assay to cytotoxin testing and cytotoxigenic culture methods. J Clin Microbiol 2009, 47(10):3211-3217.

44. Kyne L, Warny M, Qamar A, Kelly CP: Asymptomatic carriage of clostridium difficile and serum levels of IgG antibody against toxin a. N Engl J Med 2000, 342(6):390-397.

45. Bauer MP, Kuijper EJ, van Dissel JT: European society of clinical microbiology and infectious diseases (ESCMID): treatment guidance document for clostridium difficile infection (CDI). Clin Microbiol Infect 2009, 15(12):1067-1079.

46. Khanna S, Pardi D, Aronson S, Kammer P, Orenstein R, St Sauver J, Harmsen W, Zinsmeister A: The epidemiology of community-acquired clostridium difficile infection: a population-based study. Am J Gastroenterol 2012, 107:89-95.

47. Dial S, Alrasadi K, Manoukian C, Huang A, Menzies D: Risk of clostridium difficile diarrhea among hospital inpatients prescribed proton pump inhibitors: cohort and case-control studies. Can Med Assoc J 2004, 171(1):33-38.

48. Loo VG, Poirier L, Miller MA, Oughton M, Libman MD, Michaud S, Bourgault A-M, Nguyen $T$, Frenette $C$, Kelly $M$, et al: A predominantly clonal multiinstitutional outbreak of clostridium difficile-associated diarrhea with high morbidity and mortality. N Engl J Med 2005, 353(23):2442-2449.

49. Gerding DN, Johnson S, Peterson LR, Mulligan ME, Silva J: Clostridium difficile-associated diarrhea and colitis. Infect Control Hosp Epidemiol 1995, 16:459-477.

50. Mayfield JL, Leet T, Miller J, Mundy LM: Environmental control to reduce transmission of clostridium difficile. Clin Infect Dis 2000, 31:995-1000.

51. Thomas C, Stevenson M, Williamson DJ, Riley TV: Clostridium difficileassociated diarrhea: epidemiological data from western australia associated with a modified antibiotic policy. Clin Infect Dis 2002, 35:1457-1462.

52. Aldeyab MA, Kearney MP, Scott MG, Aldiab MA, Alahmadi YM, Darwish Elhajiji FW, Magee FA, McElnay JC: An evaluation of the impact of antibiotic stewardship on reducing the use of high-risk antibiotics and its effect on the incidence of clostridium difficile infection in hospital settings. J Antimicrob Chemother 2012, 67(12):2988-2996.

53. Jump RLPMDP, Olds DMRNP, Seifi NMS, Kypriotakis GMS, Jury LARNCNP, Peron EPP, Hirsch AAP, Drawz PEMD, Watts BMD, Bonomo RAMD, et al: Effective antimicrobial stewardship in a long-term care facility through an infectious disease consultation service: keeping a LID on antibiotic Use. Infect Control Hosp Epidemiol 2012, 33(12):1185-1192.

54. Nathwani D, Sneddon J, Malcolm W, Wiuff C, Patton A, Hurding S, Eastaway A, Seaton RA, Watson E, Gillies E, et al: Scottish antimicrobial prescribing group (SAPG): development and impact of the scottish national antimicrobial stewardship programme. Int J Antimicrob Agents 2011, 38(1):16-26

55. Valiquette L, Cossette B, Garant M-P, Diab H, Pépin J: Impact of a reduction in the Use of high-risk antibiotics on the course of an epidemic of clostridium difficile-associated disease caused by the hypervirulent NAP1/027 strain. Clin Infect Dis 2007, 45(2):S112-S121.

56. Anderson RM, Garnett GP: Mathematical models of the transmission and control of sexually transmitted diseases. Sex Transm Dis 2000, 27:636-643.

57. Nowak M, Anderson R, McLean A, Wolfs T, Goudsmit J, May R: Antigenic diversity thresholds and the development of AIDS. Science 1991, 254:963-969.

58. Yakob L, Clements ACA: A mathematical model of chikungunya dynamics and control: the major epidemic on réunion island. PLOS ONE 2013, 8(3):e57448.

59. Yakob L, Dunning R, Yan G: Indoor residual spray and insecticide-treated bednets for malaria control: theoretical synergisms and antagonisms. J R Soc Interface 2011, 8(59):799-806.
60. Yakob L, Yan G: Modeling the effects of integrating larval habitat source reduction and insecticide treated nets for malaria control. PLOS ONE 2009, 4(9):e6921.

61. Ferguson N, Keeling MJ, Edmunds WJ, Gani R, Brenfell BT, Anderson RM, Leach S: Planning for smallpox outbreaks. Nature 1991, 425:681-685.

62. Meyers LA: Contact network epidemiology: bond percolation applied to infectious disease prediction and control. Bull Am Math Soc 2007, 44:63-86.

doi:10.1186/1471-2334-13-376

Cite this article as: Yakob et al:: Clostridium difficile exposure as an insidious source of infection in healthcare settings: an epidemiological model. BMC Infectious Diseases 2013 13:376.

\section{Submit your next manuscript to BioMed Central and take full advantage of:}

- Convenient online submission

- Thorough peer review

- No space constraints or color figure charges

- Immediate publication on acceptance

- Inclusion in PubMed, CAS, Scopus and Google Scholar

- Research which is freely available for redistribution 